\title{
TITLE:
}

\section{$<$ Book Review> The Chimp and the River: How AIDS Emerged from an African Forest (By David Quammen)}

\section{$\operatorname{AUTHOR}(S)$ :}

McGrew, William C.

\section{CITATION:}

McGrew, William C.. <Book Review> The Chimp and the River: How AIDS Emerged from an African Forest (By David Quammen). Pan Africa News 2016, 23(1): 7-8

ISSUE DATE:

2016-06

URL:

http://hdl.handle.net/2433/216107

RIGHT:

Copyright (C) Pan Africa News. 
tations before the event were high $(\mathrm{Q} 1,5.42 \pm 0.89$; Q2, $4.98 \pm 1.02 ; \mathrm{Q} 3,5.02 \pm 0.96)$, and so was their level of satisfaction after the event $(\mathrm{Q} 4,5.44 \pm 0.78$; Q5, $4.64 \pm 1.17$; Q6, 5.19 \pm 0.87; Q7, 5.04 \pm 0.93; Q8, 5.18 \pm 0.89; Q9, $5.42 \pm 0.77)$. Examining the relationships between the scores for nine answers each respondent gave showed that they were positively correlated with each other $(r=0.30$ to $0.67, p<0.01)$ except for Q2-Q7and Q2-Q8 $(r=0.19$, 0.26, n.s.).

\section{What kind of outreach programs were preferred?}

Respondents of all age classes preferred symposia over six alternatives, while on-demand lectures and exhibitions were less preferred (Figure 3). The preference for "science cafés," which involve face-to-face presentations and conversations in casual settings, varied according to age: it was strong in the 30's group (0.70), while weak in the 60's group $(0.18)\left(\chi^{2}(6)=15.23, p<0.05\right)$. In contrast, the preference for "extension lectures," special courses usually offered by universities as social contributions, was strong in older generations (40's-70's + ), while weak in younger generations (10's-30's) $\left(\chi^{2}(6)=17.71, p<0.01\right)$.

\section{DISCUSSION}

The event was successful in terms of the number of participants, which exceeded expectations (Hosaka 2015). Most participants not only seemed satisfied with the symposium but also shared intellectual curiosity with the host researchers (Q4-8, Figure 2). In the comments for q16, many respondents noted that they admired the ambitions of the pioneers who explored Western Tanzania in the 1960s and also mentioned that they had great expectations for young scientists present at the symposium, who were full of abiding enthusiasm and brand-new methodology. This showed that the event had also been successful in terms of aims of the symposium (Hosaka 2015).

According to the results for Q9 (Figure 2), most respondents expected to attend similar outreach events in the future. In order for these events to fulfill expectations, it would be fruitful to use the results of this questionnaire to derive some suggestions for improvements, which may also be useful for other research organizations.

The first suggestion is to target a specific audience. It should be noted that the average score for Q5 (Figure 2) was slightly lower than scores for Q4 and Q6-Q8, which implies that the symposium had not met the expectations of some participants. The audience for this event was not restricted to a certain generation and it is difficult to satisfy audiences across generations. For instance, some younger participants may have expected an array of recent advancements, while some older participants may have been simply interested in accounts of the earliest days of research.

The second suggestion is to determine what kind of outreach program would fit the target audience. It seems that symposia were the most preferred format across generations (Figure 3); hence, it is important to organize symposia on a regular basis. It also seems evident that younger generations enjoy science cafés, while older generations prefer extension lectures. Considering that symposia cannot be held very often, researchers ought to exploit such alternative opportunities.

The third suggestion is to optimize public relations strategy depending on the target audience. In this study (q5, Figure 1), the effect of "websites" and "SNS" was present across generations but these were merely complementary as public relations tools. "Flyers," distributed at zoos in Tokyo and Yokohama, seemed effective for the middle-aged, implying that zoos are attracting middleaged visitors curious about wild animals. "Newspaper" was the strongest tool for over-sixties, while it had the least effect on younger generations, possibly due to the decline in newspaper readership. "Friends" seemed to be an important source for people ranging in age from twenties to fifties. In marketing, word of mouth communication is believed to have a major impact on consumer purchasing behavior (e.g., Chevalier \& Mayzlin 2006).

\section{ACKNOWLEDGMENTS}

We would like to express our sincere gratitude to the executive committee of Mahale 50 Tokyo and the student staff from Teikyo University of Science for their cooperation in this survey, and also to the participants who kindly completed the questionnaire.

\section{REFERENCES}

Chevalier JA, Mayzlin D 2006. The effect of word of mouth on sales: Online book reviews. J Mark Res 43:345-354.

Hosaka K 2015. Mahale 50 Kyoto, Tokyo \& Kigoma. Pan Afr News 22:14.

Hosaka K, Nakamura M 2015. Conservation and the future. In: Mahale Chimpanzees: 50 Years of Research. Nakamura M, Hosaka K, Itoh N, Zamma K (eds), Cambridge University Press, Cambridge, pp. 679-690.

Nakamura M, Hosaka K, Itoh N, Zamma K (eds) 2015. Mahale Chimpanzees: 50 Years of Research. Cambridge University Press, Cambridge.

Nishida T 2012. Chimpanzees of the Lakeshore: Natural History and Culture at Mahale. Cambridge University Press, Cambridge.

Nishida T, Nakamura M 2008. Long-term research and conservation in the Mahale Mountains, Tanzania. In: Science and Conservation in African Forests: The Benefits of Longterm Research. Wrangham RW, Ross E (eds), Cambridge University Press, Cambridge, pp. 173-183.

\section{<BOOK REVIEW> The Chimp and the River: How AIDS Emerged from an African Forest}

By David Quammen

New York: W.W. Norton, $174 \mathrm{pp}$,

ISBN: 978-0-393-35084-5, 2015. \$13.95 (USA), paperback

\section{William C. McGrew \\ Division of Biological Anthropology, Dept. of Archaeology and Anthropology, University of Cambridge, UK}

Most of us who study chimpanzees probably will pick up a book that has our subject species in its title, out of curiosity. (Even if the demeaning abbreviation, "chimp", is used!) I did so in a Borders bookshop, having never 


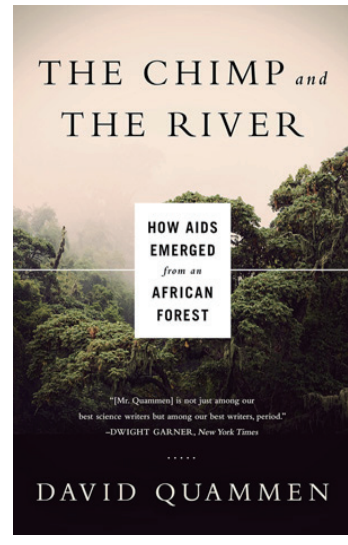

heard of this book before then. I HAD heard of its predecessor, Spillover. Animal Infections and the Next Human Pandemic, by the same author, published in 2012. As it turns out, Quammen extracted a chapter from the first book and then adapted it for publication as another book on its own.

Quammen is an awardwinning science writer, probably best known for an earlier book, The Song of the Dodo. He has written before about non-human primates, notably for National Geographic, about Gombe and Jane Goodall, but in this book, he travels to central Africa to seek first-hand information about his topic. In a nutshell, the chimpanzee in the title is the hypothetical individual Pan t. troglodytes who passed on to a hunter the virus that became HIV1. The river is the Sangha River, the hypothetical avenue down which the virus travelled to reach Brazzaville and Leopoldville (now Kinshasha), from whence it spread out to infect the globe.

Quammen makes clear his aim in the introduction: To trace backward from the current pandemic of HIV-AIDS to its origin, then to follow its progress via history, epidemiology and accident to its "spillover." Thus, according to him, it is a saga with three main characters: chimpanzee, human and virus. This attempt at reconstruction is a real challenge, for by the time HIV-AIDS was identified, its origins were lost in the past, to be elucidated only by retrospective inference, from limited, piece-meal, and non-random evidence. His thesis is simple: Just over a century ago, a single SIV-infected chimpanzee was killed or butchered by a single African hunter from southeastern Cameroon. That event of zoonoses (transmission from animal to human) was the trigger, from whence all else proceeded.

Technically, the book is admirable. It is written in elegant and intelligible English, all lean and no fat. It has 25 chapters, short and punchy, often with cliff-hanging final sentences, to keep the reader moving on. The good news is that there are 139 endnotes that allow the reader to follow up any point, and there are about 100 references in which to do so. The 10-page index is detailed and useful. The less-good news is that there are no illustrations, not even a map of the key places of the journeys made by the virus, or the author.

The argument is by plausibility, based on the first recovered evidence of the virus (dating back to 1908), then on later medical evidence collected sporadically and serendipitously in the ensuing decades, until modern studies, principally by Beatrice Hahn and colleagues, have sought and obtained new data, in proactive, hypothesis-testing mode. These latter field studies have utilised non-invasive methods, by extracting antibodies from urine or virus fractions from faeces, thus allowing cooperation with ongoing projects done by field primatologists. However, the timing of the key events can be inferred only by the molecular clock, via comparison of variants in nucleotide substitutions, as no actual chronology is possible.

So, what are its limits? First, it is out of date. Basically it is the story up to Keele et al. (2009), which revealed that wild chimpanzees do suffer from their own version of AIDS. Second, as presented here, the evidence from wild chimpanzees comes only from Gombe, which is notable, given that $P$. $t$. $t$. in Cameroon is a different subspecies from $P$. $t$. schweinfurthii in Tanzania. Since then, $\mathrm{SIV}_{\mathrm{cpz}}$ has been found in other populations of $P$. $t$. s. and P. t. t. (Rudicell et al. 2011) but not (yet) in P. t. v. (Leendertz et al. 2011). Third, Quammen is clearly committed to a narrative (Cut Hunter Hypothesis), to which the evidence is made to fit. To give a simple example, the possibility of human to animal transmission (anthroponoses?) as an alternative explanation is never mentioned. Presumably this is ruled out because SIV is said to be older and more diverse than HIV (to put it simplistically). Certainly, humans preying on apes is more common than apes preying on humans, but the latter does occur (Frodo's consumption at Gombe of a human infant, while its mother and others could only watch in horror, being a graphic example). And, it turns out that $\mathrm{SIV}_{\mathrm{cpz}}$ may be no more varied that HIV-1, M lineage, with its nine subtypes. So, perhaps it is not so clear who infected whom?

So, why should a chimpologist read this book? First, field primatologists (e.g., Jane Goodall, Richard Wrangham) play prominent roles in the story. Second, it provides a succinct and readable account of the SIV-HIV origins story, to which students and others can be referred for background reading. Thus, it offers a basis for answering testing questions about the relationship between chimpanzees and HIV-AIDS. Third, on a completely different level, it reminds us that physical contact with both human and chimpanzee blood is a risky business, wherever and however it may occur.

\section{REFERENCES}

Keele BF, Jones JH, Terio KA et al. 2009. Increased mortality and AIDS-like immunopathology in wild chimpanzees infected with SIV $_{\mathrm{cpz}}$. Nature 469:515-519.

Leendertz SAJ, Locatelli S, Boesch C et al. 2011. No evidence for transmission of $\mathrm{SIV}_{\mathrm{wrc}}$ from western red colobus monkeys (Piliocolobus badius badius) to wild West African chimpanzees (Pan troglodytes verus) despite high exposure through hunting. BMC Microbiol 11:24.

Rudicell RS, Piel AK, Stewart F et al. 2011. High prevalence of simian immunodeficiency virus infection in a community of savanna chimpanzees. J Virol 85:9918-9928.

Pan Africa News, Vol. 23, No.1

Published in June, 2016

Address: c/o Human Evolution Studies,

Dept. of Zoology, Faculty of Science, Kyoto Univ., Kyoto, 606-8502, JAPAN

TEL: (+81)75-753-4108

FAX: $(+81) 75-753-4115$

E-mail: pan.editor@gmail.com

URL: http://mahale.main.jp/PAN/

$\underline{\text { ISSN: }}$ 1884-751X (Print), 1884-7528 (Online) 